Submitted December 23, 2004; submitted, revised, March 25, 2005; accepted March 31, 2005.

Funding support: This project was supported by Prescription for Health, a national program of The Robert Wood Johnson Foundation with support from the Agency for Healthcare Research and Quality.

Acknowledgments: We would like to thank several groups for their important role in the successful completion of this investigation. For its generous funding and energizing vision, we thank the Robert Wood Johnson Foundation. For its recruiting of subjects and collaboration with community partners, we thank the following MAFPRN clinics: CentraCare Clinic/Long Prairie, Creekside Family Physicians, Fairview Clinic/Eden Prairie, Park Nicollet Clinic/Minnetonka, Parkview Medical Clinic, Payne
Avenue Clinic, Parkview Medical Clinic, Phalen Village Clinic, Soteria Family Health Center, Starbuck Clinic, and Willmar Family Practice Clinic. For their active involvement in informing our early conceptualizations of this work, and ongoing availability to patients seeking assistance with important behavioral change, we thank the following community partners and advisors: Hazelden Foundation, Minnesota Partnership for Action Against Tobacco, National Institute of Diabetes and Digestive and Kidney Diseases, Be Active Minnesota, Blue Cross Blue Shield of Minnesota, and the Park Nicollet Institute.

\section{References}

1. Botelho R. My Health Habits Journal. Rochester, NY: MHH Publications; 2003.

\title{
Reducing Tobacco Use and Risky Drinking in Underserved Populations: The Need for Better Implementation Models
}

\author{
Bonnie McRee, $\mathrm{MPH}_{i}{ }^{1}$ Jennifer Granger, $\mathrm{MPH}_{i}{ }^{2}$ Thomas Babor, $\mathrm{PbD}, \mathrm{MPH}{ }_{i}{ }^{1}$ Ingrid Feder, $\mathrm{MD}_{i}{ }^{3}$ Audie Horn, $\mathrm{Jr}_{r} \mathrm{PA}-\mathrm{C}, \mathrm{CDE}_{i}{ }^{4}$ \\ Judith Steinberg, $M D_{i}^{5}$ Keith vom Eigen, $M D, P b D, M P H^{6}$ \\ 'University of Connecticut Health Center, Department of Community Medicine and Health Care, Farmington, Conn \\ ${ }^{2}$ Connecticut Primary Care Association, Hartford, Conn \\ ${ }^{3}$ Community Health Center, Inc, New London and Groton, Conn \\ ${ }^{4}$ Katahdin Valley Health Center, Island Falls and Patten, Me \\ ${ }^{5}$ Harbor Health Services, Boston, Mass \\ ${ }^{6}$ Burgdorf/Fleet Health Center, St Francis Hospital and Medical Center, Hartford, Conn
}

Ann Fam Med 2005;3(Suppl 2):S58-S60. DOI: 10.1370/afm.362.

Conflicts of interest: none reported

CORRESPONDING AUTHOR

Jennifer Granger, MPH, Director of Clinical Affairs, Connecticut Primary Care Association, 90 Brainard Rd, Suite 101, Hartford, CT 06114, jgranger@ ctpca.org

\section{PURPOSE}

T The prevalence of many health behavior risk factors (eg, smoking, risky drinking, physical inactivity) are highest among uninsured and Medicaid-eligible populations. ${ }^{1}$ Screening and brief behavioral counseling in high-volume Federally Qualified Health Centers (FQHCs) are key elements of a cost-effective public health approach to the early identification and management of high-risk patients. This project examined 3 different ways to implement a combined screening and brief intervention $(\mathrm{SBI})$ program for smokers and at-risk drinkers in FQHCs.

\section{METHODS}

Practices in 6 New England FQHCs were randomized to 1 of 2 SBI implementation models: the clinician model, in which a physician or physician's assistant conducted the brief counseling services; or the specialist model, in which a staff medical assistant or nurse conducted the brief counseling services. In all, 24 clinicians and 13 specialists participated. A seventh practice was selected to test a health educator model, in which an external assistant who was not a staff member conducted the SBI services. Key staff from the general medicine departments at each site participated in a 3-hour continuing medical education-accredited training session before beginning a 4-month implementation phase. The implementation phase was followed by a 4-month sustainability phase during which the sites had less frequent contact with the research team, but continued to conduct SBI and were monitored for progress. SBI was conducted using standardized procedures for risk factor screening combined with brief counseling for smoking cessation or reducing risky drinking. ${ }^{2,3}$

The relative penetration of each model was assessed, along with changes in clinicians' attitudes, knowledge, 
and practice behavior. We used 2 primary outcome variables to measure the uptake of SBI procedures in participating practices: the proportion of patients screened and the proportion of patients at risk who received a brief intervention. We computed the first measure by dividing the total number of screenings by the number of patient clinic visits for participating staff during the study period. To compute the second measure, we divided the number of patients who received an intervention by the number of patients screening positive for each of the risk behaviors. Secondary outcome measures (eg, changes in clinicians' attitudes and knowledge) were assessed using a medical staff survey ${ }^{4}$ administered to participating medical staff before the training and again at the end of the implementation phase. We also conducted poststudy debriefing interviews with medical staff. Institutional review board approval was granted before the beginning of the study.

\section{LESSONS LEARNED}

Across the 7 sites, 3,502 patients were screened during the 8 -month study period. Because of the large number of participating clinicians, the majority of patients were screened at sites using the clinician model (64\%), while fewer were screened at sites using the specialist model $(28 \%)$ and the health educator model $(8 \%)_{i}$, however, the health educator model produced a substantially higher overall screening rate $(82 \%)$ than the clinician model $(18 \%)$ or the specialist model $(25 \%)$. In addition, screening rates were higher in the smaller practices (ie, those with lower patient volume), although patient load per clinician was similar across sites, with a mean of 75 patients per week per clinician. During the implementation phase, rates in the 2 smallest clinics (1 clinician model and 1 specialist model) were higher than $90 \%$, whereas less than $6 \%$ of eligible patients were screened at the 2 higher-volume clinics ( 1 clinician model and 1 specialist model).

Of patients screened, approximately $40 \%, 44 \%$, and $38 \%$ of those at practices using the clinician, specialist, and health educator models, respectively, were current smokers. On average, the corresponding proportions of patients reporting risky drinking were $10 \%, 15 \%$, and $9 \%$. The brief intervention rates for patients who screened positive for tobacco use and risky drinking were similar across models, with two thirds of at-risk patients receiving counseling in each of the 3 models. The program was not sustained in either the clinician model or the specialist model beyond the implementation phase and was terminated early (ie, during the implementation phase) in 2 clinics due to staff burnout.

As measured by attitudinal questionnaires and poststudy debriefing interviews with 38 staff members, the majority of participating clinic staff agreed philosophically with the need to conduct SBI but found it difficult to provide the service in the course of a busy clinic day. Lack of time was identified as the primary barrier to successfully implementing the program. Overall, clinic staff indicated that they had gained new skills from the experience and were more confident in providing brief interventions to patients. They nevertheless reported that the program was too burdensome to conduct on a regular basis. To reduce the burden, staff suggested "limiting SBI to preventive visits" or to specific times of the year (eg, "tobacco screening month"). Staff also indicated that they intended to screen patients for risk behaviors "more often now." Despite these good intentions, the data did not substantiate such claims. When asked during the debriefing interview which model would be most effective, staff unanimously chose the health educator model.

\section{CONCLUSIONS}

Based on the lessons learned from our project, we suggest the following take-home messages:

- High prevalence of behavioral risk factors at FQHCs make these sites ideal for SBI programs.

- Screening is the key component of such programs. Once screening is conducted, it is highly likely that brief interventions will be delivered to those at risk.

- Because current staffing at FQHCs is inadequate to implement and sustain SBI activities, an alternative model that carves out key SBI elements to dedicated health educators may have considerable promise within a broader public health approach to behavioral risk factor reduction.

Although the results of our study should be interpreted within the limits of its quasi-experimental design, our findings are consistent with previous research indicating that behavioral risk factor screening programs for alcohol abuse and tobacco use are difficult to implement unless critical logistical barriers are overcome. ${ }^{4,5}$ Even though our data indicate that brief interventions will be delivered to a large proportion of patients who screen positive for risky drinking or smoking, current clinic staffing does not support the necessary office systems to implement and sustain the screening service. Within higher-volume clinics particularly, frontline staff have increasing demands to expand their standard intake procedures, leaving little time for additional activities such as risk behavior screening. The development of effective implementation models for routine or opportunistic screening is therefore essential, especially for high-volume clinics that treat a great number of the at-risk population. Our study shows that a model in which the SBI elements 
are "carved out" to an external staff person substantially improves implementation and allows more effective use of clinicians in a supporting role, such as reinforcing the intervention with patients.

One potential limitation of the health educator model is that clinic staff won't accept an outsider. Contrary to this admonition, the current project demonstrated that the health educator becomes incorporated as part of the staff in a very short period of time, and other research indicates that the model works well in a variety of health care settings. ${ }^{2}$ Another potential limitation is the sustainability of the model. One solution for sustaining this model in FQHCs is to use students in health-related professional programs (eg, public health, social work, nursing, medicine). These students could be a consistent source of low-cost health educator staff at FQHCs during their practicum or independent study experience, and the program could be replicated in most large cities. This approach, however, will require the development of standardized practicum curricula within different professional schools to train students in the techniques and practice of SBI.

To read or post commentaries in response to this article, see it online at http://www.annfammed.org/cgi/content/full/3/Suppl_2/S58.

Key words: Mass screening; Federally Qualified Health Centers; Medicaid; alcohol drinking; tobacco; smoking; medically uninsured; low-income population; counseling; primary health care; medically underserved area
Submitted December 21, 2004; submitted, revised, March 2, 2005; accepted March 16, 2005.

Funding support: This project was supported by Prescription for Health, a national program of The Robert Wood Johnson Foundation with support from the Agency for Healthcare Research and Quality.

Acknowledgments: We would like to thank all participating staff at Katahdin Valley Health Center; Community Health Center, Inc; Harbor Health Services; and the St Francis/University of Connecticut Primary Care Center at the Fleet/Burgdorf Health Center. We would especially like to thank Donna Damon, Pat Gaudet, Bruce Gould, Karen McMillan, Stacy Yearwood, and Janice Vendetti for their assistance in the administration and coordination of the program.

\section{References}

1. Fine LJ, Philogene GS, Gramling R, Coups EJ, Sinha S. Prevalence of multiple behavioral risk factors in the United States: results from the 2001 National Health Interview Survey. Am J Prev Med. 2004;27(2 Suppl):18-24.

2. Yphantides N, Kelso D, Whalen H. Summary: Screening and Brief Intervention for At-Risk Drinkers Delivered by Physician Extenders in Primary Care Settings. San Diego, Calif: Altam Associates, Inc; 2003.

3. Babor TF, Higgins-Biddle J, Higgins P, Gassman R, Gould B. Training medical clinicians to conduct alcohol screening and brief intervention. Subst Abuse. 2004;25:17-26.

4. Babor TF, Higgins-Biddle J, Dauser D, Higgins P, Burleson J. Alcohol screening and brief intervention in primary care settings: implementation models and predictors. J Stud Alcohol. In press.

5. Coups EJ, Gaba A, Orleans CT. Physician screening for multiple behavioral health risk factors. Am J Prev Med. 2004;27(2 Suppl):34-41.

\section{Collaborative Goal Setting to Improve Lifestyle Behaviors: Lessons Learned From NOPCRN}

Sandra Puczynski, PbD, Kevin Phelps, DO, Allan Wilke, MDi Rollin Nagel, PbD, Daniel Hickey, JD, MBA,

Dalynn Badenhop, $P b D_{i}$ Frank Repka, PhD, RDi Wendy Boone, RN, MPH

Medical University of Ohio at Toledo, Toledo, Ohio

Ann Fam Med 2005;3(Suppl 2):S60-S62. DOI: 10.1370/afm.364.

Conflicts of interest: none reported

CORRESPONDING AUTHOR

Sandra Puczynski, PhD, Medical University of Ohio, 3025 Arlington Ave., Toledo, OH 43614, spuczynski@meduohio.edu

\section{PURPOSE}

$\mathrm{W}$

e examined the effectiveness of a multicomponent lifestyle activity intervention for overweight or obese patients with impaired fasting glucose (prediabetes). The physician-directed counseling intervention included collaborative goal setting with patients to achieve specific changes in physical activity and nutrition behaviors. Nurse surveillance was used to provide reinforcement and to monitor progress.

\section{METHODS}

We randomized 88 adult patients with prediabetes and a body mass index of $25 \mathrm{~kg} / \mathrm{m}^{2}$ or greater to either an immediate- or a delayed-intervention group. Individual- 